\title{
Synchronous and Sequential Strategies in the Process Design of Cascade Equipment
}

\author{
Jan Groot Wassink and Imre G. Rácz "
}

Cascade or multistage equipment is characterized by the repetition of similar equipment elements in series. Process design, resulting into the main geometric and kinematic dimensions of the equipment, makes use of different strategies. These strategies, based on a process description, the (equality- and inequality) constraints and the number of degrees of freedom of the mathematical system, which describes the process, can be divided in synchronous- and sequential procedures. In a synchronous strategy no a priori requirements are made as to the distribution of a given process variable over the stages, so that the equipment dimensions are obtained simultaneously. In contrast to this a sequential strategy makes use of a priori statements resulting into stage-to-stage calculations and a decreasing number of degrees of freedom. The general theory presented with detailed information on process description, constraints and degrees of freedom, has been applied to the process design of a multi-stage centrifugal compressor.

\section{Conceptual definitions}

In a first approach chemical equipment behaviour may be characterized by the two general notions of extensity and intensity. The equipment extensity is related to the outer conditions of inputflow and supply of energy. The equipment intensity follows from the inner conditions for the process which is carried out in the apparatus and describes the required state of the process at the output in terms of pressure, temperature and concentrations as a function of the input conditions.

Now, chemical equipment may be considered as an arrangement of one or more essential equipment elements, connected either in parallel or in series. Obviously, large extensity values correspond with large sizes of equipment elements, eventually connected in parallel. Equipment, having high intensity values, may be realized by connecting the elements in series. The latter type of equipment is also indicated as cascade equipment.

In a subsequent exploration of the title of this contribution the notions of process design, synchronous and sequential strategies need further explanation: if it is assumed that design is related to dimensioning and construction of equipment then the term process design, in the sense it is used in this text, is limited to procedures which lead to a quantitative determination of the main geometrical and kinematical dimensions of chemical equipment. The important problems of the selection of materials of construction, of the estimation of mechanical strength and of the details of construction are excluded.

As has already been mentioned, process design is also a procedurial operation which, for cascade equipment, may be distinguished in synchronous and sequential (or diachronic) strategies.

A syndhronous strategy is characterized by the fact that the main dimensions of the equipment elements are calculated simultaneously. In this case the relational coupling between the equipment elements has been taken into account and no conditions have been made about a priori distributions of one or more variables over the elements. An advantage of this strategy is the larger number of degrees of freedom in the design, resulting into a larger "design space" of the apparatus; a disadvantage may be the more extensive calculations that have to be carried out in combination with the check on the calculation results in order to meet given practical requirements.

A sequential strategy is characterized by a one-to-one calculation of the equipment elements so that at first the dimensions of the first element are calculated, then those of the second element and so on. It is clear that a sequential strategy can only be established by relational de-coupling of the equipment elements, which may be realized by assuming given a priori distributions of the coupling variables over the elements.

It goes without saying that the sequential strategy leads to a decrease of the design space; on the other hand the computations are less time-consuming while the calculation results can be better controlled by an effective choice of the distribution functions as mentioned before.

\section{A general theory of process design}

As already outlined before, the aim of process design is the determination of the main (geometrical and kinematical) dimensions of chemical equipment. The design strategy for cascade equipment which may be divided into a synchronous and a sequential procedure, makes use of a relevant process description, a set of constraints and an objective function to enable an optimal design.

The relations of the process description $P$ may be described more precisely as:

- laws of conservation (of mass, energy and momentum),

- equilibrium relations (of a thermodynamical nature),

- interrelationships, subdivided in theoretical relations (e.g. viscosity as a function of temperature) and empiri-

\footnotetext{
* Prof. Ir. Drs. J. Groot Wassink and Ir. I. G. Rácz, Department of Chemical Engineering, Twente University of Technology, P. O. Box 217, Enschede/The Netherlands.
} 
cal relations (e.g. some dimensionless engineering correlations),

- definitions.

The set of constraints $C$ is composed of a number of relations which may be defined by the following two aspects:

- mathematically, the relations can be divided in equalities and in inequalities,

- the constraints may refer to either process or to equipment conditions.

Obviously, the distinction between the process description $P$ and the process equality constraints is rather vague; moreover the equipment equality constraints can, in most cases, be translated in process conditions so that it can be argued that mathematically there is no difference between the relations of the process description $P$ and the equality constraints. The inequalities either refer to process requirements on pressures $P$ (or velocities), temperatures $T$ and concentrations $C$ or to equipment requirements on strength and reliability. The process inequalities may be derived from ecological, social or inherent technical considerations, whereas the equipment inequalities in most cases refer to technical requirements exclusively. In process design the latter requirements are not considered.

The objective function $O$, consisting of one or more equality relations between the pertinent variables of the process is the function with respect to which the design is optimized. This function may have a twofold character:

- if for example the objective function indicates a maximum capacity or a minimum formation of byproduct then the function $O$ is of a physical or technical nature and may be considered to be equivalent to the relations of the process description $P$,

- if however, the objective function is the expression of a quantitative valuation so that for example the total costs will be minimized then the function $O$ has an economical character which has to be distinguished from the process relations $P$.

Within the context of this study optimization has not been emphasized.

The number of degrees of freedom $F$ plays a very important role in the process design of equipment and can be easily calculated from the number of variables $n$ and the number of equality relations $m$ according to:

$F=n-m$

in which the integer $F \geqslant 0$. The degrees of freedom $F$ also denoted as design variables have to be selected from the total number $n$ of variables. It is clear that a statistical selection is unsatisfactory; therefore a more "deterministic" procedure has been developed in which the following rules are taken into account:

- variables, having only discrete values, are taken as design variables,

- continuous variables, with appreciable restrictions of the interval of values are recommended as design variables,
- input variables are either fixed or design variables,

- for constructional purposes it may be wise to take those variables as design variables which indicate geometrical (and/or kinematical) properties of the apparatus to be designed,

- the selection of design variables may be carried out in such a way as to minimize the number of iteration loops in the computation system, which may eventually result into an a-cyclic computation structure.

The number of degrees of freedom in combination with the flexibility in the values of the design variables determines the extensiveness of the design: the so-called design space. Any real solution of the design problem is a "point in the design space". As was already pointed out in the first section the design strategies of cascade equipment could be defined as synchronous and sequential strategies respectively, in accordance with the fact that whether or not the design problem was solved simultaneously.

Due to relational coupling between the elements, in a synchronous design of cascade equipment a cyclic computationstructure may be expected.

A sequential design strategy can be established if the relational coupling between the elements is eliminated (at the expense of the number of degrees of freedom). That means a decrease in the number of design variables and consequently a decrease in design space.

In this case, at least with respect to the subsequent cascades of the equipment, an a-cyclic computation structure can be obtained. Schematically both design strategies may be represented as given in Figure 1.

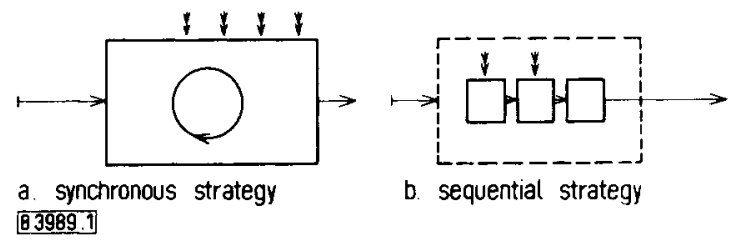

Figure 1. Schematical representation of synchronous and sequential strategies; $\mapsto$ input variable, $\rightarrow \rightarrow$ design variable, $\rightarrow$ output variable.

\section{Application to the design of a multi-stage turbo- compressor}

The general design theory developed in the second section will be made more specific by application to the design of a given type of cascade equipment: the multi-stage turbocompressor. The statement of the design problem is as follows: determine the main dimensions of a compressor for a given mass flow rate $\Phi_{\mathrm{m}}$, specified input conditions as to pressure and temperature and for a required total head $H$. It will be assumed that the range of volume flow rate $\Phi_{0}=\Phi_{\mathrm{m}} / \varrho_{0}$ and of total head $H$ is such that a multi-stage turbocompressor has to be selected.

\section{Process description $P$ and constraints $C$}

As was already outlined above, the process description $P$ may be systematically classified according to the following scheme valid for a given stage $z$ : 
- laws of conservation

mass: $\Phi_{\mathrm{z}} \varrho_{\mathrm{z}}=\Phi_{\mathrm{m}}$

energy: $W_{z}=\int_{z-1}^{z} \frac{\mathrm{d} p}{\varrho}$

- equilibrium relations

equation of state: $\frac{p_{\mathrm{z}}}{\varrho_{\mathrm{z}}}=\frac{R T_{\mathrm{z}}}{M}$ (ideal gas)

adiabatic compression: $p_{z} / \varrho^{*}{ }_{z}=p_{z-1} / \varrho^{x_{z-1}}$

- interrelationships

empirical relations: $\sigma_{\mathrm{z}}=\sigma_{\mathrm{z}}\left(A_{\mathrm{z}}\right)$ (the Cordier curve [1])

- definitions

specific speed: $\sigma_{\mathrm{z}} \equiv 2 \sqrt{\pi}\left(2 \mathrm{~g} h_{\mathrm{z}}\right)^{-3 / 4} \cdot \Phi_{\mathrm{z}-1^{1 / 2} \cdot n_{\mathrm{z}}}$ specific diameter: $A_{\mathrm{z}} \equiv \frac{\sqrt{\pi}}{2}\left(2 g h_{z}\right)^{1 / 4} \cdot \Phi_{\mathrm{z}-1}{ }^{-1 / 2} \cdot d_{\mathrm{z}}$ net energy: $W_{z} \equiv g h_{z}$

Elimination of $\varrho_{z}$ and $W_{z}$ from the equations given above, results into the following set of relations:

$\Phi_{\mathrm{z}}=\frac{R}{M} \Phi_{\mathrm{m}} \frac{T_{\mathrm{z}}}{p_{\mathrm{z}}}$

$g b_{\mathrm{z}}=\frac{\varkappa}{\varkappa-1} \cdot \frac{R T_{\mathrm{z}}}{M}\left[\left(\frac{P_{\mathrm{z}}}{P_{\mathrm{z}-1}}\right)^{\frac{x-1}{x}}-1\right]$

$\frac{T_{\mathrm{z}}}{T_{\mathrm{z}-1}}=\left(\frac{p_{\mathrm{z}}}{P_{\mathrm{z}-1}}\right)^{\frac{x-1}{x}}, \quad \sigma_{\mathrm{z}}=\sigma_{\mathrm{z}}\left(\Delta_{\mathrm{z}}\right)$

$\sigma_{\mathrm{z}} \equiv 2 \sqrt{\pi}\left(2 \mathrm{~g} h_{\mathrm{z}}\right)^{-3 / 4} \cdot \Phi_{\mathrm{z}-1}^{1 / 2} \cdot n_{\mathrm{z}}$

$\Delta_{z} \equiv \frac{\sqrt{\pi}}{2}\left(2 g b_{z}\right)^{1 / 4} \cdot \Phi_{z-1}^{-1 / 2} \cdot d_{z}$

The set of constraints $C$ may consist of the following equality relations:

the process requirement for the total head

$$
H=\sum_{z=1}^{Z} b_{\mathbf{z}}
$$

- the connections between the cascades

$$
n_{1}=n_{2}=\ldots=n_{\mathrm{z}}
$$

- the a priori distribution of the partial heads

$$
b_{1}=b_{2}=\ldots=b_{\mathrm{z}}
$$

The inequality constraints refer to limitations in rotating speed, impeller diameter and maximum allowable number of impellers per shaft.

\section{Design strategy and design space}

The number of degrees of freedom $F$ is determined from the number of relevant variables and the number of equality relations; in Table 1 the computation of $F$ is given for a synchronous strategy and for a sequential strategy (in which relation (9) is included).

The selection of the design variables obviously must include the number of impellers $Z$, so that in a synchronous design strategy as many design variables may be left as there are impellers. In a sequential design strategy however, only one design variable remains to be selected, independent of the number of impellers!
Table 1. Degrees of freedom and design strategy.

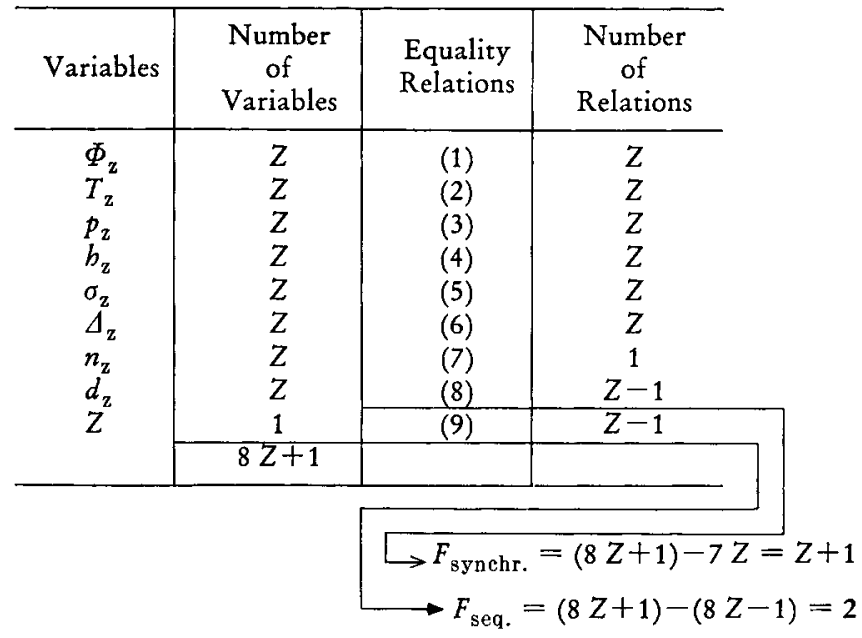

Another variable highly to be recommended as a design variable is the specific speed $\sigma_{z}$, which not only has to satisfy the relation of Cordier, but also has a limited flexibility along this curve.

Summarizing, the following design variables may be selected:

- in a synchronous strategy $Z ; \sigma_{1} ; \sigma_{2} \ldots ; \sigma_{\mathrm{z}}(F=Z+1)$

- in a sequential strategy $Z ; \sigma_{1} \quad(F=2)$

The design strategy may be represented schematically in a so-called computation structure [2]; in Figure 2 the synchronous design strategy for $Z=3$ is given, whereas in Figure 3 also for $Z=3$ the sequential procedure has been considered.

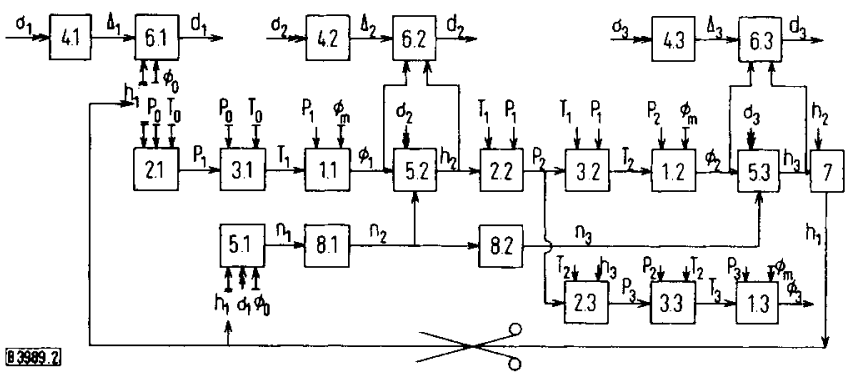

Figure 2. Computation structure of a synchronous design strategy.

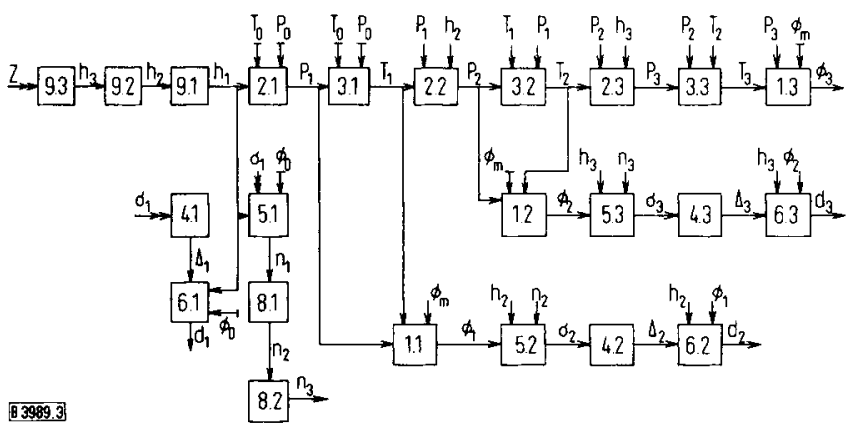

Figure 3. Computation structure of a sequential design strategy.

A comparison between both strategies gives rise to the following conclusions:

- from a design standpoint of view a synchronous strategy leads to a design space which is much more extended than in the case of a sequential strategy; 
- in the case of a synchronous strategy however, the calculation effort is much more elaborated due to the large number of design variables and the presence of iteration loops in the computation structure.

Received: October 20, 1975 [B 3989]

\section{List of Symbols}

$d \quad[\mathrm{~m}] \quad$ diameter of cascade

$g \quad\left[\mathrm{~m} / \mathrm{s}^{2}\right] \quad$ acceleration of gravity

$b$ [m] partial head

$H[\mathrm{~m}] \quad$ total head

$M[\mathrm{~kg} / \mathrm{mol}]$ molecular weight

$n \quad\left[\mathrm{~s}^{-1}\right] \quad$ angular speed

$\begin{array}{lll}p & {\left[\mathrm{~N} / \mathrm{m}^{2}\right]} & \text { pressure } \\ R & {[\mathrm{~J} / \mathrm{mol} \mathrm{K}]} & \text { gas constant } \\ T & {[\mathrm{~K}]} & \text { temperature } \\ W & {[\mathrm{~J} / \mathrm{kg}]} & \text { net energy } \\ Z & {[-]} & \text { number of cascades } \\ \Delta & {[-]} & \text { specific diameter } \\ \varkappa & {[-]} & \text { ratio of specific heats } \\ \sigma & {[-]} & \text { specific speed } \\ \Phi & {\left[\mathrm{m}^{3} / \mathrm{s}\right]} & \text { volume flow rate } \\ \varrho & {\left[\mathrm{kg} / \mathrm{m}^{3}\right]} & \text { density } \\ z & {[-]} & \text { index of cascade }\end{array}$

[1] Cordier, O.: Brennst.-Wärme-Kraft 5 (1953) S. 337/40.

[2] Rudd, D.F.; Watson, C. C.: Strategy of process engineering, Wiley, New York 1968.

\section{Kinetische Aspekte von Hochdruckreaktionen *}

\section{Gerhard Luft * *}

Der Einfluß des Drudks auf eine chemische Reaktion wird an drei wissenschaftlich wie technisch interessanten Beispielen dargelegt, und zwar dem Zerfall eines organischen Peroxids (Di-tert.-butylperoxypivalat) in Lösung, einer Gasphase-Polymerisation (A thy len-Hochdruckpolymerisation) und einer ebenfalls in der Gasphase ablaufenden Zersetzungsreaktion (thermische Athylen-Zersetzung). Es zeigt sich, daß der Druck eine Reaktion je nach Kompressibilität der Reaktanden sowie Vorzeichen und Größe des Aktivierungsvolumens sowohl beschleunigen als auch hemmen kann. Die Auswirkungen dieses Druckeinflusses auf die Führung von Hochdruckreaktionen werden kurz diskutiert.

Hohe Drücke wendet man in der Technik an, um die Ausbeute chemischer Reaktionen zu erhöhen, den im Reaktionsapparat pro Zeit- und Volumeneinheit erzielbaren Umsatz zu steigern und bei gasförmigen Komponenten die Apparatevolumina klein zu halten. Der Druck verschiebt bekanntlich bei unter Volumenverminderung ablaufenden Reaktionen das Gleichgewicht zugunsten der Reaktionsprodukte. Die Reaktionsgeschwindigkeit kann sich unter Druck um bis zu zwei Zehnerpotenzen ändern. Darüber hinaus verhindert hoher Druck in vielen Fällen eine Entmischung der Reaktanden und erleichtert dadurch sehr die Reaktionsführung. Die Geschwindigkeit

$r=k_{(\mathrm{T}, \mathrm{P})} \cdot c_{\mathrm{A}}{ }^{n} \mathrm{~A} \cdot c_{\mathrm{B}}{ }^{n_{\mathrm{B}}} \ldots$

einer chemischen Reaktion wird durch den Druck auf zweierlei Weise beeinflußt. Zum einen erhöht sich unter Druck die volumetrische Konzentration, wodurch die Reaktionsgeschwindigkeit zunimmt. Zum andern wirkt der Druck auch auf die Geschwindigkeitskonstante $k$, die also nicht nur temperatur-, sondern auch druckabhängig ist. Ihre Druckabhängigkeit wird durch die Beziehung

$\left.\frac{\partial \ln k}{\partial p}\right|_{\mathrm{T}}=-\frac{-1 v^{*}}{R T}+\left.\Sigma \boldsymbol{\nu}_{\mathrm{i}} \frac{1}{V} \frac{\partial V}{\partial p}\right|_{\mathrm{T}}$

erfaßt. Die bestimmende Größe in diesem Ausdruck ist das sog. Aktivierungsvolumen $\Delta v^{*}$. Es stellt die Differenz dar $z$ wischen dem Volumen des aktivierten Komplexes, der im Ubergangszustand durchlaufen wird, und dem Volumen der Ausgangsstoffe. Bei Assoziationsreaktionen verringert sich das Volumen im Ubergangszustand, wie in Abb. 1 angedeutet,
$\Delta v^{*}$ ist negativ, und die Geschwindigkeitskonstante nimmt entsprechend Gl. (2) mit steigendem Druck zu. Umgekehrt verhält es sich bei Dissoziationsreaktionen, wo sich die Geschwindigkeitskonstante wegen des positiven Aktivierungsvolumens mit dem Druck verringert. Bei Reaktionen in

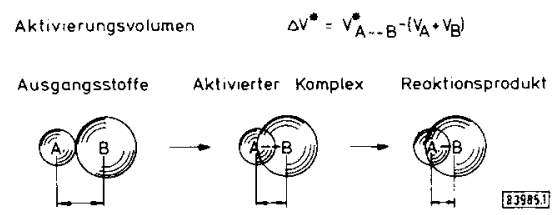

Abb. 1. Druckeinfluß auf die Reaktionsgeschwindigkeit.

Lösungen können Volumenbeiträge durch Ausbildung oder Verschwinden von elektrostatischen Bindungen im Übergangszustand hinzukommen. Auf diesen Effekt wird nicht weiter eingegangen. Der zweite Term in Gl. (2) berücksichtigt Anderungen der Geschwindigkeitskonstante durch die Kompressibilität der Reaktanden, die in der Regel vernachlässigbar klein sind.

Im folgenden werden die geschilderten kinetischen Aspekte und ihre Auswirkungen auf die Führung von Hochdruckreaktionen an drei wissenschaftlich wie technisch interessan-

\footnotetext{
* Vortrag anläßlich der Verleihung des Dechema-Preises der Max-Buchner-Forschungsstiftung am 21. Nov. 1975 in Frankfurt/M.

* Prof. Dr.-Ing. G. Luft, Institut für Chemische Technologie der T. H. Darmstadt, Petersenstr. 15, 6100 Darmstadt.
} 